\title{
Our experience in intraoperative radiotherapy applications
}

\section{İntraoperatif radyoterapi uygulamalarında anestezi deneyimlerimiz}

\author{
Güldeniz Argun ${ }^{1}$
}

Dr A Y Ankara Onkoloji Eğitim Araştırma Hastanesi, Anesteziyoloji ve Reanimasyon, Ankara

\begin{abstract}
ÖZET
İntraoperatif radyoterapi (IORT), kanser tedavisi için yeni bir modalitedir. IORT, tümörün direk görülmesi ve bu alana radyoterapi tedavisi esasına dayanmaktadır. Bir seferde, yüksek doz radyasyon, tümör yatağına, rezidü tümör dokusuna ya da sınırlı bölgesel lenf noduna uygulanmaktadır. IORT; cerrah, anesteziyolog, radyoterapist, radyolog, patolog ve cerrahi destek ekibi tarafindan multidisipliner bir yaklaşım gerektirir.

Hastanemizde Kasım 2012'den itibaren mobil Mobetron (intraoperatif incorporated SantaClara CA ) cihazı ile IORT tedavisi uygulanmaktadır. Bu hastalar IORT uygulanabilme kriterlerine göre seçilmektedir ve önceden toplanan IORT konseyinde multidisipliner olarak değerlendirilmektedir. Anesteziyolog da bu konseyin bir üyesidir ve karar aşamasından başlayarak IORT tedavisinin her aşamasında yer almaktadır. Ameliyathane ortamında yüksek doz ışın tedavisi alacak olan hastanın preoperatif hazırlığı, izolasyonu, ışınlama sırasında pozisyonu, monitörizasyonu önem taşır. Anesteziyologlar IORT hastalarının optimal şartlarda operasyona alınmasını sağlamalıdır. Operasyon sırasında damar yollarının, kabloların, solunum devrelerinin hastanın pozisyon değişikliklerinde sabit kalmasını sağlayacak önlemler alınır. Işınlama sırasında ventilasyonun durdurulduğu zamanlarda, hastaların solunum parametrelerinin korunması önem taşımaktadır. $\mathrm{Bu}$ işlemler sırasında anesrezi altındaki hastalar operasyon odasında izole olduğundan, kontrol odasından monitörizasyonun dikkatli bir şekilde takip edilmesi önemlidir. IORT uygulamaları için izole bırakılmak zorunda olan hastanın güvenliğinden anesteziyolog sorumludur ve güvenli bir anestezi sağlamak için; hastanın hazırlanmasından, rahat bir postoperatif dönem geçirmesine kadar her aşamada görev yapar. Yazımızda Kasım 2012'den günümüze kadar IORT uygulanmış 111 kanser hastasındaki anestezi deneyimlerimizi paylaşmayı amaçladık.
\end{abstract}

Anahtar kelimeler: İntraoperatif radyoterapi, anestezi yönetimi, monitörizasyon

ABSTRACT
Intraoperative radiotherapy (IORT) is a new modality for cancer treatment. IORT depends on direct visualisation of the tumour and administration radiotherapy to the involved area. Single high dose radiation is applied to tumour bed, residual tumour tissue or limited regional lymph node. IORT treatment requires a multidisciplinary approach by the surgeon, anesthesiologist, radiotherapist, radiologist, pathologist and surgical support team.

Since November 2012, IORT treatment with mobile Mobetron (intraoperatively incorporated Santa Clara) is performed in our hospital. These patients are selected according to the IORT application criteria and previously are evaluated as multidisciplinary in the collected IORT council. The anesthesiologist is the member of this council and takes place from the decision process to all stage of the IORT treatment. The preoperative preparation, isolation, position during irradiation and monitorization of the patient who will receive high doses of radiation therapy in the operating room are crucial for the anesthesia. Anesthesiologists should ensure that IORT patients are operated under optimal conditions. During the operation, precautions is taken to ensure that vessel routes, cables, and respiratory circuits remain constant during patient position changes. When ventilation is stopped during irradiation, patients' respiratory parameters are protected. Since patients are isolated under anesthesia in operating room, it is important to follow the monitor carefully from the control room. The anesthesiologist is responsible for safety of the patient who has to be isolated for IORT applications and to ensure safe anesthesia; from the preparation of the patient until comfortable postoperative period. In this review we aimed our experinces of anesthesia in 111 cancer patients who were given IORT theraphy since november 2012 until today.

Key words: Intraoperative radiotherapy, anesthesia management, monitorization. 


\section{GİRIŞ}

IORT (intraoperatif radyoterapi), cerrahi sırasında tümör yatağına ya da kalıntı tümöre doğrudan yüksek doz 1şınlamanın yapıldığı ve çevre dokuların korunduğu bir yöntemdir. $\mathrm{X}$ 1şınları ve elektron ile yapılan iki türü mevcuttur. Hastanemizde Kasim 2012'den itibaren ameliyathaneye kurulan mobil Mobetron (intraoperatif incorporated Santa Clara CA) cihazı ile intraoperatif elektron radyoterapisi yapılmaktadır. IORT; gastrointestinal sistem, yumuşak doku, başboyun, meme gibi birçok kanser tipinin tedavisinde kullanılmaktadır. Hastanemizde de günümüze kadar 100 adet meme, 9 Gastrointestinal sistem, 1 yumuşak doku, 1 nüks bukkal mukoza tümörüne IORT uygulanmiştır.

IORT kullanımı 1944'lere

uzanmaktadır(1). Tümörün direk görülmesi ve bu alana foton tedavisi esasına dayanmaktadır. $\mathrm{Bu}$ yöntemle tümör yatağına, rezidü tümör dokusuna ya da sinırlı bölgesel lenf noduna tek seferde yüksek doz radyoterapi uygulanmaktadir(2). IORT, cerrah, anesteziyolog,,radyoterapist, radyolog, patolog ve cerrahi destek ekibi tarafindan multidisipliner bir yaklaşım gerektirir(3). Bu ekip arasındaki uyum ve işbirliği çok önemlidir. IORT ve cerrahi tekniğe uygun hasta seçiminde anesteziyoloğun rolü önemlidir. Özellikle iyi bir preoperatif hazırlık, başarılı postoperatif süreç ile yakından ilgilidir.

\section{IORT ODASININ ÖZELLIKLERI:}

IORT tedavisinin ilk uygulandığ 1 Howard Üniversitesi Hastanesi'ndeki IORT odaları, standart ameliyat odasi olup, Radyoterapi bölümünde yer almaktadır. Tedavide Clinac 18 lineer akseleratör $(6,9,12,15,18 \mathrm{MeV}$ elektron 1şıma kapasiteli ve 400-500 rad/dk averajlı) isimli IORT cihazını kullanmışlardır. Standart donanımlı operasyon odas1; elektrik sistemi için "ITP panel" ile oksijen, azot, hava, pozitif basınçlı ventilasyon sistemi ve atık gaz için vakum sistemi içermektedir, bir çift hareketli cerrahi 1 şı kaynağ bulundurmaktadır. Derlenme odas1, ana operasyon odasına komşudur. Cerrahi yoğun bakım ünitesi ve patoloji bölümü aynı katta bulunmaktadır. Ana operasyon odası ile IORT odas1 arasında telefon sistemi ile direkt interkom bulunmaktadır. Duvardaki dev ayna ve televizyon kamerasindan hem hasta, hem de vital fonksiyonlar monitörden izlenebilmektedir. IORT odasına komşu alanda cerrahi yıkanma bölümü, Clinac-18 kontrol paneli, TV monitörü ve vital bulguları gösteren monitör sistemi bulunmaktadır. IORT odası ile kumanda odası güvenli bir biçimde birbirinden ayrılmıştır ve radyasyon yayılımını önleyecek şekilde izolasyon yapılmıştır. Kapının açılması radyasyonu otomatik olarak kesmektedir(2).

Bizim hastanemizde; IORT cihazı (Mobetron-intraoperatif incorporated Santa Clara, CA) ameliyathanede yer almaktadır. Standart ameliyat odasından farkı; duvarlarının ve kilitlenebilen kapısının kurşunla kaplı olmas1, yan tarafinda hastanın ve ameliyat odasının izlenebildiği kamera sistemli bir kumanda odasının bulunmasıdır.

Anesteziyolog için en kritik zaman, gerçek IORT tedavisi yapılırken hastanın geçici olarak ameliyat odasında izole olduğu zamandır (4). Anesteziyoloji ekibi, vaka için gerekli bütün cihazların, ameliyat ve IORT ekipmanların hazırlanmasından sorumludur. Hastaya ait EKG, devamlı kan basincinın izlendiği arteriyal yol, idrar atılımının monitörizasyonu, 1s1 monitörizasyonu, CVP (santral ven basinc1) ve özofagiyal monitörizasyonun sağlanmasından sorumludur. Genel anestezi altında tek seferde yüksek doz radyoterapi alan hasta izole edilir ve vital bulguları monitörden takip edilir(4).

\section{HASTANIN HAZIRLANMASI}

Önce hastanın IORT için gerekli kriterleri taşıyıp taşımadığı anesteziyolog tarafindan incelenir. Diğer hazırlıklar, rutin preoperatif hasta hazırlığındaki gibidir. (Hastanın hikayesi, fizik muayenesi, nutrisyon durumu, rutin laboratuvar çalışmaları, hemogram, akciğer grafisi, EKG, idrar analizi.) Spesifik testler gerekebilir; ayrıntılı koagulasyon testleri, pulmoner fonksiyon testleri gibi. Solunum fonksiyonlarını bozacak akciğer metastazları bulunabilir. Onkolojik hastaların sistematik değerlendirilmesi önem kazanır. Hastaların kemoterapi (KT),radyoterapi (RT) alıp almadığı sorgulanır. $\mathrm{Bu}$ hastalarda genel durum bozukluğu, kemoterapik ajanlara bağlı sistemik değişiklikler bulunabilir. Örneğin, Siklofosfamid gibi alkilleyici ajanlar, nöromusküler bloğun uzamasına neden olabilir. Yüksek konsantrasyonda oksijen tedavisinin bleomisine bağlı interstisiyel 
pnömoni ve interstisiyel fibrozisi arttırdı ğ akılda tutulmalıdır. KT, RT' ye bağlı cilt reaksiyonları not edilmelidir. Damar yolları sorunlu olabilir. Kanser hastalarının çoğu gerek hastalıkları, gerekse tedavinin yan etkileri nedeniyle yetersiz beslenirler. Kilo kaybı, kaşeksi, hipoproteinemi, hipoalbuminemi sıklıkla rastlanan bulgulardır. Preoperatif nutrisyon desteği verilmelidir. İmmünonutrisyonun ,immünosupresyonu azaltmada yararlı olduğu düşünülmektedir.

KT, RT'nin kardiyotoksik etkileri; kardiyomyopati, perikardiyal efüzyon, perikardit ,konjestif kalp yetmezliğine kadar uzanabilir. Hepatobilier sistemde; hepatomegali, karaciğer fonksiyon testlerinde bozulma görülebilir, siroza kadar gidebilir. Koagulasyon faktörlerinde azalma ve koagulopati görülebilir. Üriner sistemde; radyasyon nefropatisi, böbrek yetmezliği görülebilir.

Hematopoietik sistem, immün sistem bozukluğu görülebilir. $\mathrm{Bu}$ nedenle kanser hastaları multidisipliner incelenmeli, klinik ve laboratuvar değerleri açısından optimal düzeye getirilerek operasyon için hazırlanmalıdır. Preoperatif laboratuvar bulgularının düzeltilmesi, cerrahi komplikasyonları ve morbiditeyi önemli derecede azaltmaktadır. Örneğin; yüksek bilirubin seviyelerinin preoperatif dekompresif prosedürlerle veya baypasla düşürülmesi, aneminin, malnütrisyonun düzeltilmesi gibi. Bütün bu düzenlemeler, anestezi başarısını arttıracaktır, cerrahi mortaliteyi ve morbiditeyi azaltarak, hastanın erken derlenmesine olanak sağlayacaktır.

Hastanemizde her hafta düzenli olarak, önceden belirlenmiş bir IORT konsey ekibi (Genel Cerrahi, Radyoterapi, Anesteziyoloji, Medikal Onkoloji, Radyoloji, Patoloji ve diğer cerrahi kliniklerden gelen uzmanlardan oluşan) tarafindan IORT toplantısı yapilmaktadir. Konseyde IORT uygulanabilme kriterlerine sahip hastalar tartışılmaktadır. Hastaların yaşları, tümörlerinin yeri, büyüklüğü, uzak metastaz açısından vücut taramaları, öncesinde kemoterapi uygulama gerekliliği olup olmadığı, cerrahi uygulaması sirasında akselaratörün yerleştirilmesi ve anestezi uygulamasina ait oluşabilecek zorluklar değerlendirilir. IORT kararı alınan hastalar için ameliyat günü kararlaştırılır ve hasta ameliyat listesine alınır.
Önceden sağlanmış teknik donanım, IORT süresince sabit ve kesintisiz monitörizasyonu mümkün kılar. Burada anesteziste düssen görev, IORT odasının donanımının sağlanmasına yardım etmektir. IORT cihazi; hasta gelmeden önce çalıştırılarak kontrol edilir. Ameliyat masası, ışın verebilmeyi kolaylaştıracak ve cihazın içine girebilecek şekilde yerleştirilir. Genellikle altı boş olan ayak kısmına, baş gelecek şekilde ayarlanır. Batın, pelvis ve sakral bölge operasyonlarında, masa baş kısmı ayak kısmına gelecek şekilde ters çevrilir ve hastanın başı kapıya yakın tarafa geldiği için, anestezi cihazı, kablolar, serum askıları, gaz panelleri hastaya yakın olacak şekilde ayarlanır. Anestezi ekibi, hastanın pozisyonuna göre yer değiştirir.

\section{CERRAHİ VE ANESTEZI UYGULAMASI:}

Uygun premedikasyon yapıldiktan sonra operasyon odasina alınan hastaya standart prosedürler uygulanır. Kanama olasılığı olan operasyonlar için hastaya önceden, yeterli intravenöz yol, santral ven kateterizasyonu, intraarterial kateterizasyon, postoperatif ağrı tedavisi için indüksiyon öncesi epidural kateterizasyon, nazogastrik sonda, idrar sondası gibi girişimler yapılır. İşlem sırasında hastanın hareketsiz kalması ve ventilasyonun durdurulmas1 gerekeceğinden, kas gevşeticinin kullanılacağı, endotrakeal entübasyonun uygulanacağı genel anestezi yöntemi tercih nedenidir. Alt batın ve alt ekstremite cerrahileri için regional anestezi uygun gibi görünürse de regional anestezi uygulanmasını kısitlayacak faktörler vardır. Bunlar; pozisyonda yapılabilecek büyük değişiklikler, masaya aşırı eğim verilmesi, hastanın hiç hareket etmemesi gerekliliği ve bu ayarlamaların uzun sürebilmesinin hastayı strese sokabilmesi gibi faktörlerdir ve genel anestezi tercihimizin sebeplerindendir. Genel anestezi uygulamalarımızda fentanil, propofol azotprotoksit / oksijen karışımıyla, sevofluran ve kas gevşetici olarak da nondepolarizan ajan kullanılmıştır

Cerrah, kanser cerrahisinin prosedürlerini uygular. İlk hedef, tümörü lokalize etmek ve frozen için biyopsi almaktır. Sonraki adım, frozen sonucunda belirlenen hastalığın yaygınlığının, metastazlarının ve rezektabilitesinin saptanmasıdır. Bölgesel lenf 
nodlarının örneklemesi de incelemeyi tamamlar ve sonucu anlamlı k1lar.

Meme operasyonlarında; operasyon öncesinde Nükleer Tıp tarafından radyoaktif (teknesyum 99) madde ile işaretleme yapılır. Operasyonda radyoaktif tutulum gösteren kitle çıkarılır, patolojiye gönderilir. Axiller tutulum varsa, axilladan alınan lenf bezi de patolojiye gönderilir. Cerrahi sınır negatifse ve axiller örnekleme normalse IORT hazırlığına başlanır. Cerrahi sinır pozitif gelirse rezeksiyon genişletilir ve yeniden cerrahi sınır patolojiye gönderilir. Cerrahi sinır negatifse IORT hazırlığına başlanır. İstenilen cerrahi sınıra ulaşılamazsa mastektomiye geçilir, IORT 'tan vazgeçilir.

Abdominal, pelvik ya da sakral girişimlerde, baş ve ayak yönleri ters çevrilmiş masaya hasta da başı ayak kısmına gelecek şekilde ters yatırılır. Yani baş, ayakucunda, ayaklar cihaza doğrudur (Resim 1). Bu vakalarda genellikle rezidü tümör kaldığı düşünülen alana 1şınlama yapılır. Masanın ayak k1smı indirilir, hasta jinekolojik pozisyonda olduğu gibi kalçası mümkün olduğunca masanın en ucuna getirilir. Boşta kalan bacaklar bağdaș kurdurularak masanın üzerinde toplanır ( Resim 2) ve hasta cihazın içine doğru ilerletilir. KBB, ortopedi vakalarında da IORT uygulanacağı zaman operasyonun yerine göre pozisyon ayarlanır.

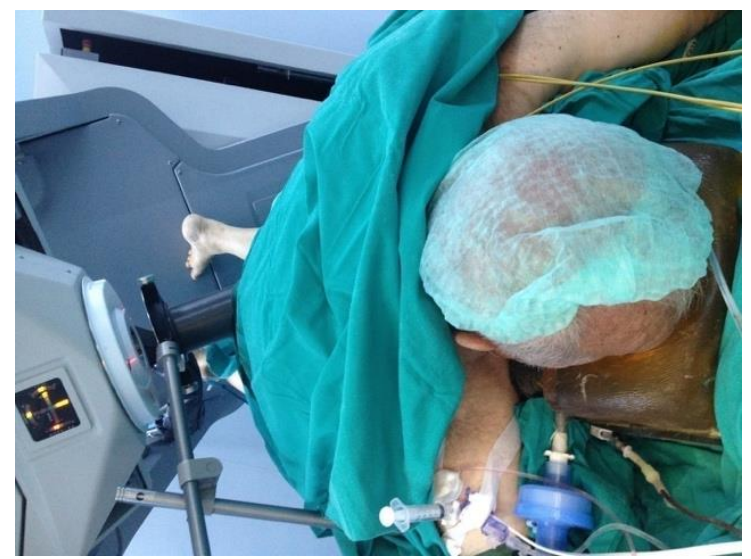

Resim 1: Hastanın başı ayakucunda olup ayakları cihaza doğru konumlandırılmış

IORT'a hazırlık aşamasında cerrahlar, çıkarılan bölgenin genişliğine uygun akseleratörü steril şartlarda yerleştirir. Bu aşamada anesteziyolog devreye girer, ameliyat masasıyla hastayı cihazın içine yerleştirir. Damar yollarının, kateterlerin, solunum devrelerinin ve endotrakeal tüpün korunması önem taşır. IORT uygulaması sırasında radyoterapist tedavinin sonuna kadar ameliyathanede yer alır, operasyonu izler, uygun akseleratörün yerleştirilmesine yardım eder ve uygulanacak ışın dozunu ayarlar.

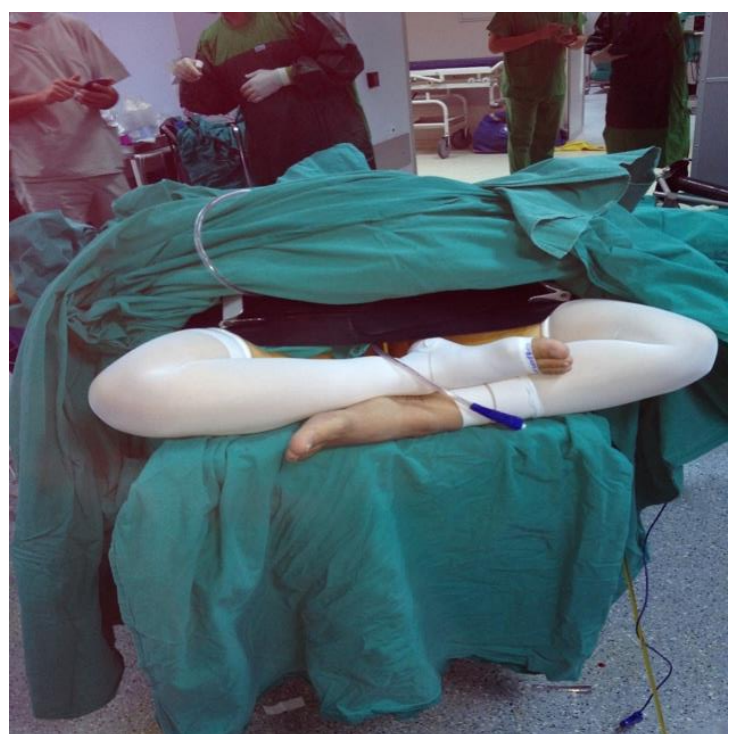

Resim 2: Bacaklar bağdaş kurdurulmuş

Cihazın, 1şınlanacak alanı tam olarak algılaması, lazer panelle anlaşılır. Masaya pozisyon değişiklikleri (yan pozisyon, baş yukarı gibi) yapmak gerekebilir. Lazer panelde (+) şeklinde yeşil ışı̆̆ın görülmesi, ışınlanacak alanın tam olarak saptandığını gösterir. $\mathrm{Bu}$ görüntüyü elde edebilmek için, hastanın solunum hareketlerinin de engellenmesi gerekmektedir. Bunun için önceden ek doz kas gevşetici yapılır, hastaya giden oksijen konsantrasyonu arttırılır. End-tidal değeri artma eğiliminde olabilen hastalara frekans arttırılarak end-tidal değeri hafif düşürülebilir. Sonra manuel solunum ayarına geçilir, ayar yapılana kadar hasta solutulmaz. İşlem uzun sürer, parsiyel oksijen saturasyonu (SPO2) 95 değeri altına düşerse, ara verilip hiperventilasyon yaptırılip tekrar manuel solunuma geçilir. Lazer panelde $(+)$ şeklinde yeşil ışık görüldüğünde, yani 4 koordinattan da 1şın uygulanacak alana eşit yaklaşım sağlandığında, tüm ekip operasyon odasını boşaltır, kapı kilitlenir, yandaki kameralı odaya geçilip, hasta ve monitör ekrandan izlenir. Radyoterapi uzmanlarınca hesaplanan işın dozu hastaya uygulanır. Yaklaşık 1 dakika süren işlem sonunda kap1 açılır, ekip operasyon odasina girer, anestezi cihazı tekrar mekanik ventilasyon moduna geçirilir. 
Hastanın SPO2 ve end-tidal değerleri değişmişse normale getirilir. Ameliyat masası cihazın içinden çıkarılıp, normal konumuna getirilir. Cerrahi ekip sterilizasyonu sağladıktan sonra akseleratörü çıkarır, operasyonu tamamlar ve anestezi ekibi tarafindan hasta uyandırma aşamasına geçilir.

Hastaların, IORT ve cerrahinin sonunda durumlarına göre (ventilasyonunun, bilincinin, koruyucu reflekslerinin varlığının değerlendirilmesi ile) derlenme odasına ya da yoğun bakım ünitesine yatırılmas1 kararlaştırılır. Hastalar 24 saatlik periyotta anestezik komplikasyon yönünden izlenir.

Bazı hastalara ileriki periyotta eksternal 1şın tedavisi gerekebilir. (Boost tedavisi denir, 10 grey dozunda eksternal 25 gün verilir ve genç yaştaki hastalar için uygulanır). Tek doz parsiyel 1şınlamada ise hastalar 21 grey doz alır. Bu doz, akseleratörler yardımıyla doğrudan operasyon bölgesine uygulanır ve eksternal uygulamadan farkl1 olarak, çevre dokular korunur. Hastalar, klinik doktorları tarafindan uygun görülen zamanda taburcu edilirler.

Malign tümör tedavisinde ülkemizde oldukça yeni bir yöntem olan IORT tedavisi hastanemiz ameliyathanesinde 2012 yilindan beri uygulanmaktadır. ABD'de IORT 1976'dan beri uygulanmaktadır. Howard Üniversitesi'nde 8 y1l boyunca 148 IORT vakası alınmış ve tedavi süresince herhangi bir istenmeyen durum ya da komplikasyonla karş1laş1lmamıştır(1). Hastanemizdeki IORT uygulamalarımızda da tedavi sürecinde herhangi bir istenmeyen durumla karşılaşılmadı.

Japonya'dan da benzer veriler gelmiştir(5). Ancak işlemi gerçekleştiren bazı cerrahlar, anesteziyologlar, diğerleri, operasyon odasinda maruz kalacakları radyasyon tehlikesinden veya hastanın odada yalnız birakılmasından dolayı tedavi yöntemine sıcak bakmamışlardır ve yöntemi sik kullanmayı tercih etmemişlerdir.

\section{REFERANSLAR}

1. Henschke U, Henschke G, ZurTecnik Der Operationsbestrahlung. Strahlentherapie 1944; 74:223-239.

2. Goldson A, Ashayeri E, Espinoza MC, et al. Single high dose intraoperative electrons for advanced
Mannaerts ve arkadașları, 1994 ve 2000 yılları arasında rektal malignite sebebiyle IORT tedavisi almış 106 hastayı retrospektif olarak incelemişlerdir. Bu hastalara genel ve epidural anestezi birlikte uygulanmıştır. Hastaların operasyon sürelerini, intraoperatif kanama miktarlarını, yoğun bakımda kalma sürelerini ve mortalitelerini değerlendirmişlerdir. İyi bir preoperatif hazırlıkla ve hastanın optimal şartlarda operasyona alınmasinin, postoperatif morbidite ve mortalite üzerine etkili olduğunu kanıtlamışlardır(6).

Kathryn ve arkadaşları çalışmalarında, IORT vakalarında anestezi uygulamalarında laringeal maske kullanımınının, spontan solunuma izin vermesi nedeniyle, tidal volüm ve solunum hızında olabilecek büyük değişikliklerle, elektron 1şınlarının foküslenmesini zorlaştıracağını belirtmişlerdir. $\mathrm{Bu}$ nedenle endotrakeal tüple sağlanan havayolu ve kas gevşetici kullanımının, solunumsal uygunsuzlukları ortadan kaldıracağını savunmuşlardır(7). Bizim vakalarımız da entübe edilerek, güvenli havayolu sağlanımıyla IORT tedavisi almıșlardır.

\section{SONUÇ}

Otörlere göre, IORT güvenli ve pratik bir yöntemdir. Klinik ve terapotik değerler hala kontrollü çalışmalarla devam etmektedir. Yeni IORT cihazlarındaki gelişmelerle teknik olarak daha çok sayıda hasta tedavisinin mümkün olacağ1 görüşü yaygınlaşmaktadır. Biz uygulama yaptığımız hastalarımızda gerek operasyon ve IORT sirasinda, gerekse anesteziden derlenme periyodu sirasinda olumsuz herhangi bir değişiklikle karşılaşmadık. Biz de teknik açıdan daha geliştirilmiş cihazlarla, daha fazla sayıda hastaya, operasyon sırasında hiç hareket ettirmeden, optimize şartlar sağlanarak daha konforlu ve güvenilir anestezi uygulamaları yapılabileceğini düşünmekteyiz.

stage pancreatic cancer : Phase 1 Pilot Study. Int J Radial Oncol Biol Phys 1981;7:869-874.

3. E.Ashayeri, MD, T. Dallas, MD, A. L. Goldson, MD, M. Selon,MD, D.T. Conseption, MD andJ.C.Manning, MD. Anesthesia in intraoperative radiotheraphy patients. Journal Of The National Medical Association. 1986;78:193-199. 
4. Stoelting RK. Psycological preperation and preoperative medication. Anesthesia 1981;1:157201.

5. Abe M, Takahashi M. Intraoperative radiotheraphy: The Japanese experience. Int J Radiat Oncol Biol Phys. 1981;7:863-868.

6. Mannaerts GH1, Van Zundert AA, Meeusen VC, Martijn H, Rutten HJ. Author information.
Anaesthesia for advanced rectal cancer patients treated with combined major resections and intraoperative radiotherapy. Eur $\mathrm{J}$ Anaesthesiol. 2002;19(10): 742-8.

7. Kathryn M, Glynn, MD, Adam I. Riker, MD. Anesthetic considerations for intraoperative radiationtheraphy. TheOchsnerJournal. 2015; 15: 438-440. 